\title{
Transport Planning, Organisation and Management
}

\author{
Elżbieta Macioszek, Grzegorz Sierpiński, Marcin Staniek, Ireneusz Celiński \\ Transport Systems and Traffic Engineering Department, Faculty of Transport / Silesian University of Technology \\ Krasińskiego 8, 40-019 Katowice, Poland \\ elzbieta.macioszek@polsl.pl; grzegorz.sierpinski@polsl.pl; marcin.staniek@polsl.pl; ireneusz.celinski@polsl.pl
}

\begin{abstract}
High traffic volumes in transport networks are currently among the key issues addressed by municipal authorities of contemporary cities. The complex nature of traffic and its consequences, such as e.g. emission of exhausts and noise, negative environmental impact, costs, time, deterioration of public space, requires appropriate transport planning, organisation and management conducted in a comprehensive manner, aimed at maintaining balance in the transport system. On the other hand, efficient transport management and organisation requires information concerning transport behaviour patterns observed in the travelling population. What proves to be crucial is the knowledge of the travel source, destination as well as the travelling mode and individual traffic routes. Measurements conducted for purposes of traffic modelling do not usually allow for precise analysis and visualisation of characteristics of transport multimodality. For the sake of sustainable development of transport, modal split must be oriented towards eco-friendly solutions, and thus also towards an increase in the share of multimodal travel. Such a need also stems from the growing dynamics of travelling and relocation of traffic generators and absorbers. The authors conducted studies of transfers made in the travelling population on a real time basis, i.e. with increased accuracy compared to traditional research methods typically applied so far. Under the Green Travelling project, mobile surveys of transfers made in the territory of the city of Gliwice (Upper Silesian conurbation, Poland) were conducted by monitoring transfers of persons through tracking of mobile phones featuring GPS receivers. The studies were aimed to enable identification of the inhabitants' transfers, paying special attention to the chains generated in the process. Such an approach makes it possible to account for the specificity of multimodal travels and their dynamic evolution in traffic modelling.
\end{abstract}

Keywords: Travel behaviours, transport, public transport, individual transport

\section{Introduction}

Upgrading or expanding elements of the transport network should be based on results of an economic and functional analysis. However, it is only possible to conduct such an analysis properly and without errors when one is in disposal of a suitable tool which makes it possible to reflect the travels being made in the transport network by means of a matrix of the number of travels as well as the travel distribution in the transport network. In order to establish the basic functions of models, using which it is possible to calculate the matrix of the number of travels and the spatial distribution of these travels in the transport network, one must first identify characteristics of travel behaviour patterns observed among inhabitants of the analysed area and among those travelling to this area on a regular basis, for instance to school, to work, to the university, as well as irregularly, i.e. for private purposes. The most important characteristics which define the travelling persons' behaviours within the given area primarily include the following [1], [2], [3], [4]:

- distributions of probability of choosing the given means of transport depending on how long the intended travel is;

- distributions of probability of travelling time depending on the means of transport;

- distributions of probability of the travel destination choice;

- travel resistance functions depending on the travel length, time and destination;

- composition of means of transport;

- structure of use of individual means of transport;

- travelling speed distributions in individual means of transport;

- information concerning mobility of people and means of transport;

- distributions of travel chains;

- functions determining variability of use of the travel chain elements throughout a day by inhabitants of the given area; 
- distributions of walking time to and from individual means of transport.

While conducting measurements of travel behaviour patterns for purposes of traffic modelling, in the first stage, one determines the travel source and destination, the motivation to travel, the means of transport (or a collection of ones) chosen to complete the transfer or potentially also intermediate travelling points. All these activities are often conducted with accuracy enabling breakdown into areas of more than a dozen thousand square metres, referred to as transport territories. What is required in order to learn about transport related needs observed in the given area is advanced questionnaire surveys [5] conducted both at homes and in locations being traffic generators, such as hypermarkets, railway stations etc. However, such surveys are sadly characterised by low accuracy of data, since one is missing e.g. precise information about routes or receives incorrect data due to respondents' difficulties in recreating the actual course of travel, and in many cases those surveyed are unfortunately also the less mobile persons.

Moreover, measurements conducted for purposes of traffic modelling do not usually allow for precise analysis and visualisation of characteristics of transport multimodality. For the sake of sustainable development of transport, modal split must be oriented towards eco-friendly solutions, and thus also towards an increase in the share of multimodal travel [6], [7], [8], [9], [10], [11], [12], [13], [14], [15]. Such a need also stems from the growing dynamics of travelling and relocation of traffic generators and absorbers. Therefore, what proves particularly important is precise observation of such

processes in the transport network. Evolution of telemetric systems and increasingly common application of GPS modules in mobile phones have made it possible to implement new solutions in the sphere of traffic measurement.

The authors conducted studies of transfers made in the travelling population on a real time basis, i.e. with increased accuracy compared to traditional research methods usually applied so far. Under the Green Travelling project implemented as a part of the ERANET Transport III programme (more extensively addressed in papers [16], [17], [18], [19], [20]), mobile surveys were conducted by monitoring people's transfers through tracking of mobile phones featuring GPS receivers. The studies were aimed to enable identification of the inhabitants' transfers, paying special attention to the chains generated in the process. Such an approach makes it possible to account for the specificity of multimodal travels and their dynamic evolution in traffic modelling. An equally innovative approach to surveys conducted abroad to study transfers made in the travelling population within the given area have only been discussed in several publications, including [21], [22], [23], while the authors of this article undertook their research in the territory of the city of Gliwice (Upper Silesian conurbation, Poland) where no studies had previously been conducted by monitoring transfers of persons through tracking of mobile phones with GPS receivers.

\section{Sources of data concerning travel behaviour patterns displayed by inhabitants of the given area}

The basic source of data concerning transfers made by inhabitants of the given area is principally the information obtained from the preference questionnaire used as an instrument while studying travel behaviour patterns. As an indirect and complementary source, also travel planners may deliver relevant information in this respect. While a travel planner application is being used, sets of various data are retrieved in the background, to be subsequently used for purposes of planning of sustainable transport development. Travel planners make it possible to investigate and archive travel start and end points, but also the means of transport used and many more parameters of the travel. Collecting data on transportrelated preferences and behaviours observed in the given area using all the available travel planners leads to formation of Big Data sets which may support processes ensuring sustainability of transport. To review an example of such a tool, one may refer to specialised travel planner named Green Travelling Planner (GT Planner), developed as a deliverable of an international project implemented under the ERA-NET Transport III Future Travelling Programme entitled "A platform to analyze and foster the use of Green Travelling options (GREEN_TRAVELLING)". The planner is based on the GTAlg algorithm for establishing routes in a transport network based on pre-set criteria. The planner in question has been illustrated in Fig. 1. It depicts GT Planner's basic feature. Fig. 1 shows a transfer path between the chosen starting point and end point of the travel. The route thus defined is determined by the criteria pre-set by the GT Planner user. 


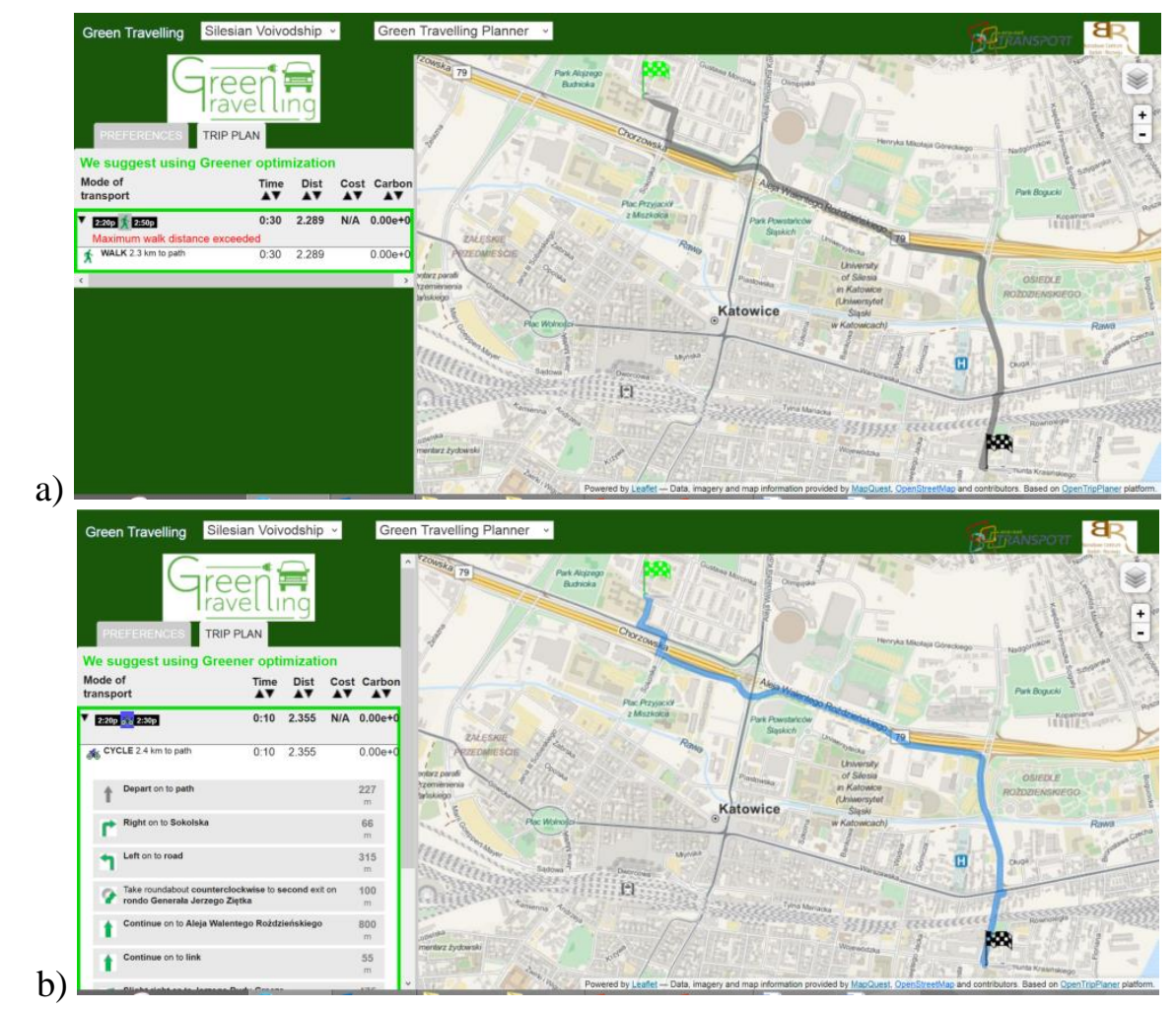

Fig. 1: Example of the transport network route determination using GT Planner: a) walk only and quicker option selected, b) bike only and quicker option selected. Source: [16].

What the authors of this publication proposed was a procedure to study travel behaviour patterns using mobile devices. A mobile application named AP1 was developed for purposes of the Green Travelling project and it enables recording of transfers by tracking positions of GPS units, at the same time keeping records of travel destinations and means of transport for the transfers examined. It was dedicated to popular mobile devices, such as smartphones or tablets. A detailed description and hardware requirements of the application have been provided in paper [24].

The application records output data incoming from a GPS module, linear accelerations received from an accelerometer as well as data concerning the travel destination and the means of transport which are defined by the mobile device user (in a travel $\log$ ). The travel destination is interpreted as motivation (why the given person travels) and defined as follows: home, work, school, shop, sports, health etc. A means of transport is the transfer mode defined as follows: walk, bike, motorcycle, car, bus, tram, trolleybus, train etc. The GPS unit location means, in this case, data of longitude, latitude and ellipsoidal height recorded according to the WGS84 standard (one of standards for co-ordinate systems used in geographic information systems). In the same data set, other parameters such as date, time and instantaneous speed are recorded. The data acquired from the accelerometer concern the linear accelerations recorded by the device in three dimensions, XYZ. The recorded data are stored in the device memory in a pre-defined standard. Once the travel monitoring function is activated, the application runs constantly in the operating system background. It is not even disabled while typical mobile device functions are performed. Moreover, the application records transfers irrespective of the respondent's actions (whether one keeps a travel log or not).

\section{Survey of transfers made by the travelling population}

The survey of transfers made by the travelling population were conducted for purposes of traffic modelling for the Upper Silesian conurbation area (17 municipalities of Silesian Province, Poland). The measuring methodology, based on the use of mobile phones, and the selected results obtained for one of the cities, i.e. Gliwice, have been discussed in this article. This method complemented both the basic research and the basic transfer parameters with an option of representing travel behaviour patterns displayed by the travelling population on a higher level of accuracy. For the sake of the survey, each respondent received a mobile phone with a GPS unit and a SIM card. Those surveyed were requested to maintain 
their usual, typical behaviour and to travel according to their natural needs (i.e. not forcing them to act specifically so that the survey would not affect the travelling population's behaviour patterns) with the device supplied by the survey organisers switched on. Moreover, each respondent was obliged to keep a travel log (using the same application, i.e. AP1). The application was used by those surveyed to record every travel and then to indicate the motivation behind the travel source and destination, thus obtaining combinations such as home-school, work-home etc. The last step was for the respondent to indicate the current travelling mode (means of transport used). Such a procedure was implemented in order to maximise the accuracy of the data on the means of transport, destination and source of the travel. Once these options were selected, the program would initiate a task run in the background which monitored the respondent's transfer. In cases of broken chains, on each change of the means of transport, the respondent was obliged to log the change accordingly in the AP1 application using adequate options of choice. Having completed the journey, the respondent would pick yet another suitable option in the application, thus finalising the travel data recording. As a result of all these actions, travel behaviour patterns were precisely represented assuming a pre-set time interval (with the accuracy of hundredth parts of a second). It should also be noted that such high precision is only applied to accelerometer calibration. Consequently, each person's travel could be parameterised as a function of multiple variables:

$$
P=f(S M, D M,\langle I P\rangle,\langle M T\rangle, G P S(t), d s(t))
$$

where:

SM - source motivation to travel (i.e. travel starting point);

$D M \quad$ - destination motivation to travel (i.e. travel end point);

IP $\quad-$ set of intermediate points;

$M T \quad-$ set of means of transport used while travelling;

$G P S(t)$ - instantaneous GPS signals received at points other than $S M, D M$ and $I P$;

$V(t) \quad$ - momentary velocity $[\mathrm{km} / \mathrm{h}]$

$d s(t) \quad$ - momentary path accretion $[\mathrm{km}]$.

Consequently, the results obtained by application of the assumed travel behaviour measurement methodology based on the use of mobile devices reflect the actual characteristics of the transfer made by the user in the transport network most closely. Considering the flaws of the measuring method in question, one should primarily mention interferences caused by the respondents remaining in such places as underground parking lots and tunnels or walking inside buildings. However, it is only under such conditions that the measuring quality may temporarily drop, and regardless of the foregoing, it is still above the level of accuracy attained using traditional measuring methods.

\section{Results obtained for the city of Gliwice}

The results obtained in the course of the survey made it possible to verify the legitimacy of the measuring method assumed. Selected results have been discussed below, and they may (when measurements are conducted on a sufficiently numerous sample) be used to draw conclusions concerning travel behaviour patterns displayed by the travelling population within the given area in a more extensive manner compared to a traditional approach which entails a transport-related questionnaire. Some of the activities made possible by comprehensive travel records are as follows:

- Accurate determination of travel start and end points (by eliminating potential errors in assigning travels to a transport territory) and precise identification of transfer routes, which enable the actual distribution of traffic streams to be mapped on the transport network (for the given sample), being an option unavailable in the case of a solely questionnairebased survey (Fig. 2a).

- Option of analysing the dynamics of change in the travels made in time (including determination of rush hours), highlighting differences observed depending on the motivation, as well as possibility for defining characteristics of traffic load in the chosen area of the transport network (Fig. 2b).

- Establishing changes in the flow of traffic through velocity profiling for individual travels in distribution on the transport network - option unavailable in questionnaire-based surveys (Fig. 3a). 


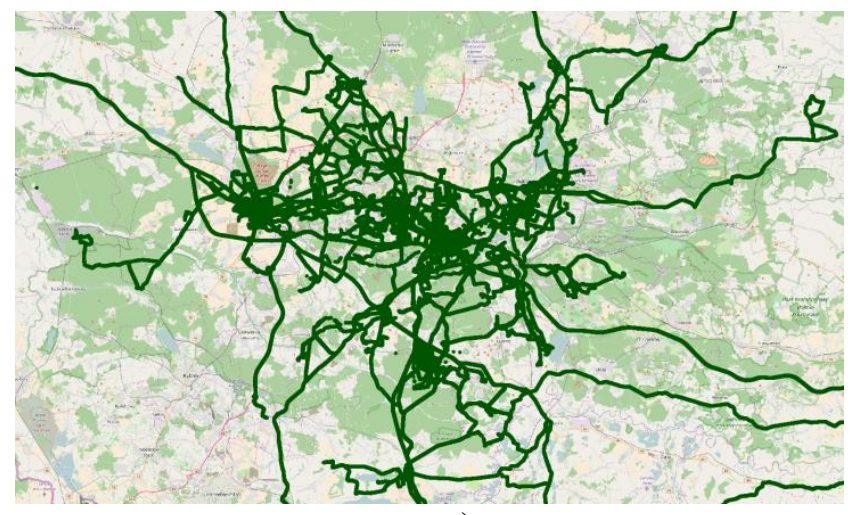

a.)

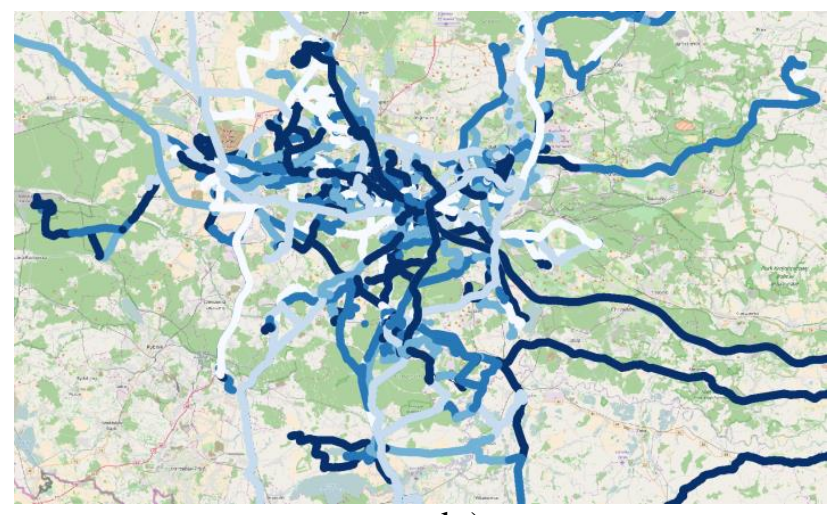

b.)

Fig. 2: a). Representation of all travels recorded in the survey; b). Travels within the Upper Silesian conurbation territory according to the time of the day when they were made. Grading: light blue colour marks morning hours; the darker the colour, the later the hour during the day.

Source: Authors' own research using the Quantum GIS application and Open Street Map blueprints.

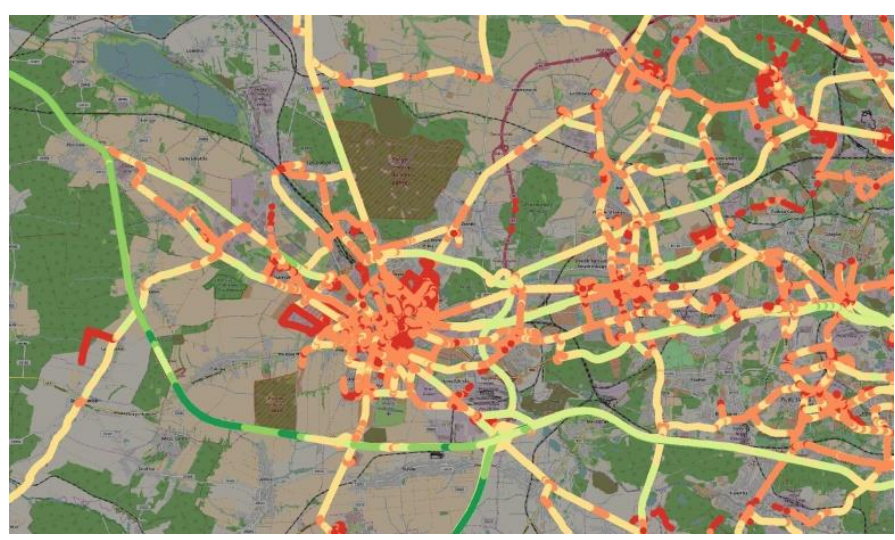

a)

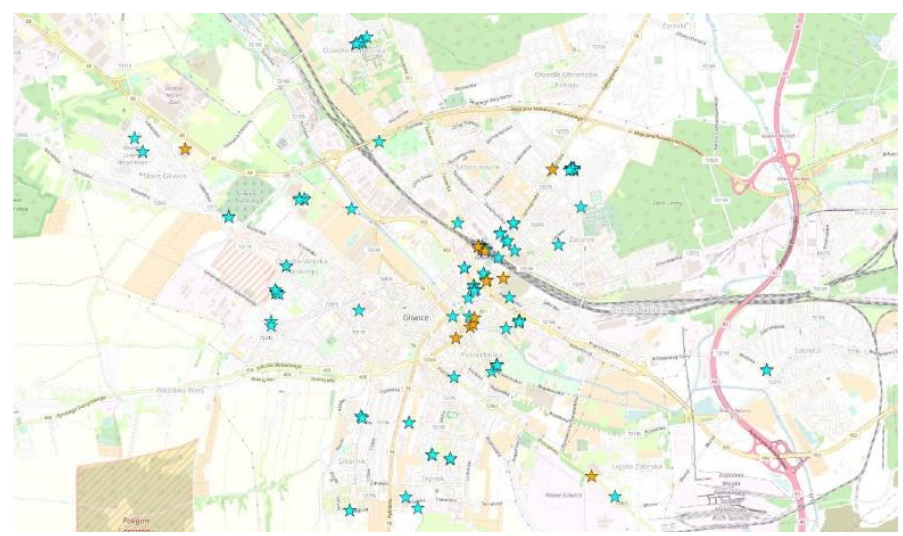

c)

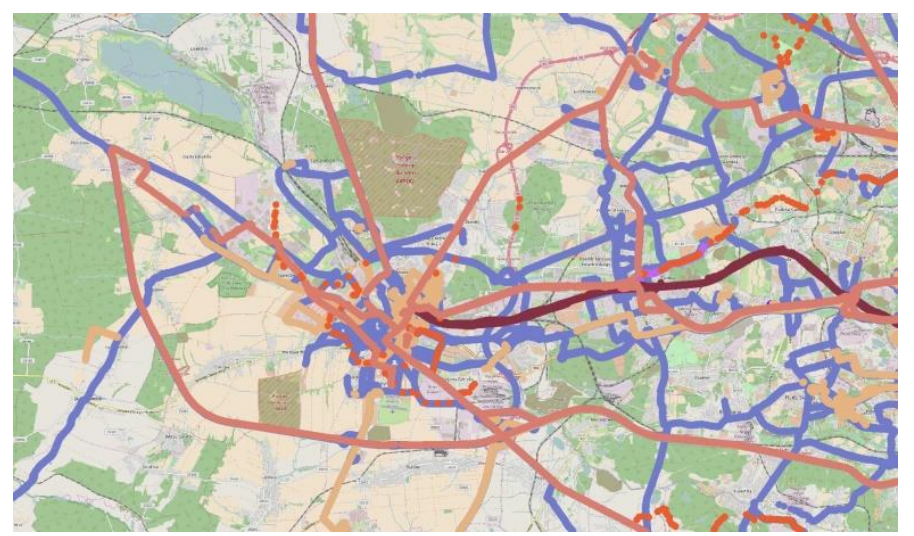

b)

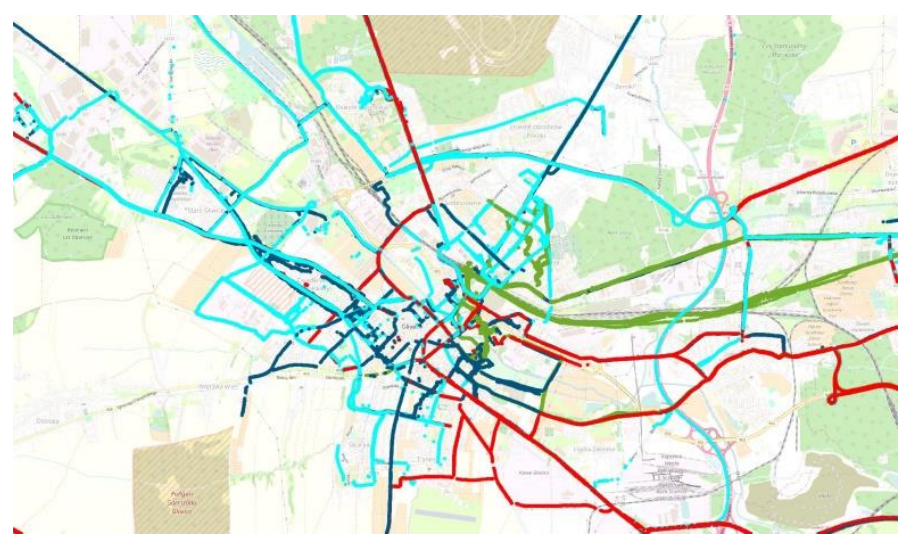

d)

Fig. 3: Analysis results obtained for the city of Gliwice: a). Velocity profiles. Grading: red colour marks extremely low velocity; orange and yellow tints mark higher velocities; green marks the highest velocity; b). Breakdown of travels according to types of transfer chains - multimodality. Different colours correspond to various travel chain configurations; c). Locations where one boards and leaves the means of public transport (change points); d). Breakdown of travels according to motivation. Green colour marks education-related travels (home-school-home); red - work (home-work-home), light blue - other home-related travels (home-otherhome), dark blue - non-home-related travels.

Source: Authors' own research using the Quantum GIS application and Open Street Map blueprints. 
- Obtaining information on the means of transport used with accurate determination of the time and the start and end points for each travel stage.

- Classification of multimodal travel chains observed (Fig. 3b) by analysing frequency of occurrence of individual travel chains for different travelling motivations, time, area etc.

- Identification of change points most willingly used by respondents (Fig. 3c).

- Identification of routes in a breakdown according to motivation types (Fig. 3d) - typically, traffic models are narrowed down to four motivation types: home-work-home, home-school-home, home-other-home and non-home-related.

- Determination of locations (transport network elements) clearly less popular among the travelling population - in this case, such research may provide support for establishing territorial availability with the accuracy of individual means of transport and, more importantly, follow respondents' subjective assessments and not only indicators stemming from objective premises.

- Identification of the public space use.

- Identification of load of transport change points

- Identification of parking points.

- Identification and estimation of waiting times in the transport network.

When the research is conducted on a larger sample, the analysis of results obtained using the aforementioned measuring methodology provides grounds for drawing broad-scale and high-accuracy conclusions concerning the current needs of the travelling population, and it may prove supportive in making decisions of major importance for the functioning of the transport system in the given area, since it may be applied in traffic modelling, organisation of division of transport-related tasks, planning and routing of public collective transport lines, siting of public collective transport stops, travel planning (especially in multimodal travelling), planning, designing and building junctions and change points, $\mathrm{P} \& \mathrm{R}$ type parking areas, and in a more distant time perspective, assigning priorities in road traffic control systems and in the process of implementing uniform transport tariffs.

\section{Conclusions}

Travel behaviour patterns are sets of parameters describing a travel being planned or actually made in the transport network. Contemporary surveys of travel behaviours displayed by inhabitants of specific areas are based on more than traditional questionnaires, and use travel planners (as well as car navigation tools) making it possible to obtain Big Data sets which prove particularly useful in identification of both actual and suppressed transport preferences (i.e. unfulfilled behaviours). Sustainable development of transport requires knowledge on all types of transport-related behaviours and preferences that can be recorded. Not until the full picture of behaviour patterns and transport preferences observed in transport network is obtained may modal split be developed in an appropriate manner. In this article, the authors have addressed the results of a survey conducted in Gliwice by application of yet another method enabling measurement of actual transport behaviours. It is their proprietary application dedicated to popular mobile devices, such as smartphones or tablets, successfully used under the Green Travelling project. The research precision attained in the study, resulting from the GPS accuracy, as well as the set of data thus recorded provide substantial support for planning, organisation and management of transport in the chosen area. Not only does the knowledge concerning transfers obtained by application of the measuring method in question make it possible to assess the current status of the transport system, but also enables identification of the impact exerted by the efforts undertaken by municipal authorities on the changes observed in transport behaviour patterns displayed by the travelling population. This method also allows for practical implementation of a dynamic return information channel connecting transport network administrators and users.

\section{Acknowledgements}

The present research has been financed from the means of the National Centre for Research and Development as a part of the international project within the scope of ERA-NET Transport III Future Travelling Programme "A platform to analyze and foster the use of Green Travelling options (GREEN_TRAVELLING)". 


\section{References}

[1] PTV Plannung Transport Verkehr, Visum user manual. Analysis and Planning of Transport Networks. Karlsruhe, 2001.

[2] A. Pande and B. Wolshon, Traffic Engineering Handbook. 7th Edition. New Jersey, the Institute of Transportation Engineers, John Wiley \& Sons, 2016.

[3] E. Cascetta and A. Carteni, "A quality-based approach to public transportation planning: theory and a case study," International Journal of Sustainable Transportation, vol. 8, no.1, pp. 84-106, 2014.

[4] G. Sierpiński, M. Staniek and I. Celiński, "Travel behavior profiling using a trip planner," Transportation Research Procedia, vol. 14C, pp. 1743-1752, 2016.

[5] US Department of Transportation. Federal Highway Administration, 2009 National Household Travel Survey. User's Guide. Version 2, updated 2011, Washington, 2011.

[6] S. Jäppinen, T. Toivonen and M. Salonen, "Modelling the Potential Effect of Shared Bicycles on Public Transport Travel Times in Greater Helsinki: An Open Data Approach," Applied Geography, vol. 43, pp. 13-24, 2013.

[7] D. Simons, P. Clarys, I. De Bourdeaudhuij, B. De Geus, C. Vandelanotte and B. Deforche, "Why do young adults choose different transport modes? A focus group study," Transport Policy, vol. 36, p. 151-159, 2014.

[8] E. Macioszek, G. Sierpiński, M. Staniek and I. Celiński, "Smarter and greener city by using travel planners to inform and educate people - recommendations under the green travelling project," Winter Conference 2016: "New Pressures on Cities and Regions," Regional Studies Association, the Global Forum for City and Regional Research, Development and Policy, London, 2016.

[9] G. Sierpiński, E. Macioszek, M. Staniek and I. Celiński, "Big data concerning travel preferences as a means to support decision making in the field of environmentally friendly urban development," Winter Conference 2016: "New Pressures on Cities and Regions," Regional Studies Association, the Global Forum for City and Regional Research. Development and Policy, London, 2016.

[10] E. Macioszek and G Sierpiński, Contemporary Challenges of Transport Systems and Traffic Engineering. Lecture Notes in Networks and Systems 2. Springer International Publishing Switzerland, 2017.

[11] E. Macioszek, "Application of Intelligent Transport Systems in road transport for providing travellers with quick and efficient information," Logistyka, vol. 4, pp. 2983-2993, 2014.

[12] E. Macioszek, "Architecture of intelligent transportation systems in the world and in Poland," Archives of Transport Systems Telematics," vol. 7, no. 3, p. 22-26, 2014.

[13] S. Boren, L. Nurhadi, H. Ny, K. Robert, G. Broman and L. Trygg, "A strategic approach to sustainable transport system development - part 2: the case of a vision for electric vehicle systems in southeast Sweden," Journal of Cleaner Production, vol. 140, no. 1, pp. 62-71, 2017.

[14] M. Kadłubek, "Examples of sustainable development in the area of transport," Elsevier Procedia Economics and Finance, vol. 27, pp. 494-500, 2015.

[15] C. Curtis and T. Perkins. (2016, November 26). Travel behaviour: a review of recent literature. Impacts of transit led development in a new rail corridor. Working paper No. 3. Department of Urban and Regional Planning. Curtin University [Online]. Available: http://urbanet.curtin.edu.au/

[16] Green Travelling, A platform to analyse and foster the use of Green Travelling options. Project Proposal. The ERANET Transport III: Future Travelling, 2013.

[17] G. Sierpiński, M. Staniek and I. Celiński, "Research And Shaping Transport Systems With Multimodal Travels Methodological Remarks Under The Green Travelling Project," in Proceedings of ICERI2014 Conference, Seville, 2014, pp. 3101-3107.

[18] G. Sierpiński, I. Celiński and M. Staniek, "Using Trip Planners In Developing Proper Transportation Behavior," International Science Index, Part III, vol. 8, no 11, pp. 482-490, 2014.

[19] G. Sierpiński, I. Celiński and M. Staniek, "Adaptive model of sustainable business development against the example of the Conurbation of Upper Silesia and Dąbrowa Basin," International Journal of Economics And Statistics, vol. 4, pp. 210-221, 2016.

[20] G. Sierpiński, "Technologically advanced and responsible travel planning assisted by GT Planner," in Contemporary Challenges of Transport Systems and Traffic Engineering, Lecture Notes in Network and Systems vol. 2, E. Macioszek and G. Sierpiński Ed., Springer, 2017, pp. 65-77. 
[21] M. Araki, R. Kanamori, L. Gong and T. Morikawa, "Impacts of seasonal factors on travel behavior: basic analysis of GPS trajectory data for 8 months," in Serviceology for Smart Service System. Springer Japan, 2017, pp. 377-384.

[22] J. Wolf, W. Bachman, M. Oliveira, J. Auld, A. Mohammadian, P. Vovsha and J. Zmud, J., Applying GPS Data to Understand Travel Behaviour. Volume II: Guidelines. NCHRP Report 775. Transportation Research Board, Washington, 2014.

[23] Y. Yuan, M. Raubal and Y. Liu, "Correlating mobile phone usage and travel behaviour - A case study of Harbin, China," Computers, Environment and Urban Systems, vol. 36, no. 2, pp. 118-130, 2012.

[24] G. Sierpiński, I. Celiński and M. Staniek, "Rejestracja zachowań komunikacyjnych w czasie rzeczywistym jako wsparcie organizacji i zarządzania transportem," Logistyka-nauka, vol. 3, pp. 5273-5280, 2015. 